\title{
Modelling of fatigue crack growth in Inconel 718 under hold time conditions - application to a flight spectrum
}

Erik Lundström, Kjell Simonsson, Tomas Månsson and David Gustafsson

\section{Linköping University Post Print}

\section{Tweet}

N.B.: When citing this work, cite the original article.

Original Publication:

Erik Lundström, Kjell Simonsson, Tomas Månsson and David Gustafsson, Modelling of fatigue crack growth in Inconel 718 under hold time conditions - application to a flight spectrum, 2014, Advanced Materials Research, (891-892), 759-764.

http://dx.doi.org/10.4028/www.scientific.net/AMR.891-892.759

Copyright: Trans Tech Publications http://www.ttp.net/

Postprint available at: Linköping University Electronic Press http://urn.kb.se/resolve?urn=urn:nbn:se:liu:diva-104812 


\title{
Modelling of fatigue crack growth in Inconel 718 under hold time conditions - application to a flight spectrum
}

\author{
Erik Lundström $^{1, \mathrm{a}}$, Kjell Simonsson ${ }^{1, \mathrm{~b}}$, Tomas Månsson ${ }^{2, \mathrm{c}}$, David Gustafsson ${ }^{3, \mathrm{~d}}$ \\ ${ }^{1}$ Division of Solid Mechanics, Department of Management and Engineering, Linköping University, \\ SE-58183 Linköping, Sweden
}

${ }^{2}$ GKN Aerospace Engine Systems, SE-46181 Trollhättan Sweden

${ }^{3}$ Siemens Industrial Turbomachinery AB, SE-61283 Finspång, Sweden

aerik.lundstrom@liu.se, bkjell.simonsson@liu.se, 'tomas.mansson@gknaerospace.com, ddavid.gustafsson@siemens.com

Keywords: Fatigue crack propagation, Inconel 718, Hold time effects, Crack growth modelling

\begin{abstract}
Gas turbine operating cycles at high temperatures often consist of load reversals mixed with hold times; the latter occurring either as cruise for aero engines or at continuous power output for land based turbines, but also at low frequency loading conditions, e.g. slow "ramp up" of engine thrust. The hold time conditions cause the crack to grow by intergranular fracture due to material damage near the crack tip, thus rapidly increasing the crack growth rate. Since the damaged zone will affect the crack propagation rate due to cyclic loadings as well, the complete load history of a component therefore has to be considered. The crack propagation model presented in this paper is based on the damaged zone concept, and considers the history effect in the form of damaged zone build up during hold times, and subsequent destruction as the crack propagates onwards by rapidly applied load reversals. By incorporating crack closure for handling different $R$-values, an aero engine component spectrum is evaluated for a surface crack at $550{ }^{\circ} \mathrm{C}$. The result shows a good correlation to model simulation, despite the complexity of the load spectrum.
\end{abstract}

\section{Introduction}

Predicting life of hot turbine components always presents a challenge, where e.g. the interaction between different load modes, i.e. rapid cycling vs. more slowly applied loads or hold times, can have a great influence on the life time expectancy. The phenomenon has been investigated by several authors and it has been found that the hold times result in material damage at the crack tip, causing the crack to grow by intergranular fracture and thus strongly increase the crack growth rate, cf. $[1,2,3]$. Although many others have dealt with the problem before, either by modified Paris law expressions, cf. [4, 5, 6] where a pure time dependent part and a pure cyclic part forms a linear summation model, or by more physically based models, cf. [7, 8] where damage, driven by e.g. oxygen diffusion, is incorporated into the modelling of crack growth, work is still needed in order to understand the interaction and history effects between load modes. It has also been shown that the increase in crack growth rate is caused by an embrittlement of the grain boundaries [9], and that a hold time block followed by an applied block of continuous cycles also affects the latter one by an increased crack growth rate [10], as the crack propagates through a damaged zone caused by the hold time block. Thus, the importance of considering the load history of a component becomes increasingly important as the resulting life can be strongly affected by such interactions. In this paper, a damage mechanism inspired model is used $[11,12]$, where the damage accumulation in front of the crack tip controls the crack growth rates during hold times and rapid cyclic loadings, thus interpreting the load history dependent interactions between different parts of the load spectrum. 


\section{Method}

Experimental Procedure. Fatigue crack growth tests were performed at $550{ }^{\circ} \mathrm{C}$ on Inconel 718 with an approximate grain size of $10 \mu \mathrm{m}$ using $\mathrm{Kb}$-type specimens with rectangular cross sections of 4.3 $\times 10.2 \mathrm{~mm}$. Crack growth was monitored by potential drop and subsequent SIF evaluation [13] was done by assuming a semi-circular crack front. In all tests the SIF of consideration was the deepest point of the crack geometry. For more details about material and experimental procedure, see e.g. [14]. Testing has been conducted at two sites; calibration test (see below) at Linköping University, and flight spectrum test at GKN, Trollhättan, both with the same batch of material.

Crack Growth Modelling. The physical entity which governs the crack growth rate is, as previously discussed, the damaged zone in front of the crack tip. The size of this zone, here denoted $D$, will determine how fast the crack will grow, both during the build up, but also during the subsequential destruction of the zone. As mentioned above, the crack growth behaviour will thus heavily depend on the load frequency as well as the load history. By identifying, (i) hold time crack growth that occurs at very low stress rates, and (ii) the cyclic crack growth taking place at high load frequencies, as two extremes or governing states, a crack propagation law can be formed by applying the damaged zone concept with scale factors to control the crack propagation rate. The complete model, for this 1D case, can be seen in Table 1; for a more comprehensive description, see [11, 12].

Table 1: Crack growth law.

Time dep. crack growth rate:

$\dot{a}_{t}=\frac{D}{D_{\max }} \cdot C_{t} K_{\max }^{n_{t}}$

Time dep. scale function:

$C_{t}=C_{0 t}\left(1-\exp \left(\frac{-B_{t}}{1-\frac{D}{D_{\max }}}\right)\right) \quad B_{t} \geq 0$

Time dep. damaged zone growth rate:

$\dot{D}_{t}=\dot{m}-\dot{a}_{t}$

Damage mechanism growth rate:

$\dot{m}=C_{t} K_{\max }^{n_{t}}$

Cyclic crack growth:

$\Delta a_{c}=\int_{t_{1}}^{t_{2}} \dot{a}_{c} \mathrm{~d} t=\int_{0}^{1} \frac{\mathrm{d} a_{c}}{\mathrm{~d} N} \mathrm{~d} N$

$\frac{\mathrm{d} a_{c}}{\mathrm{~d} N}=S_{c} \cdot C_{c}\left[\frac{1-f}{1-R} \Delta K\right]^{n_{c}}$

$f=\frac{K_{o p}}{K_{\max }}=\left\{\begin{array}{lc}\max \left(R, A_{0}+A_{1} R+A_{2} R^{2}+A_{3} R^{3}\right) & R \geq 0 \\ A_{0}+A_{1} R & -2 \leq R<0\end{array}\right.$

$A_{0}=\left(0.825-0.34 \alpha+0.05 \alpha^{2}\right)\left[\cos \left(\pi \sigma_{\max } / 2 \sigma_{0}\right)\right]^{1 / \alpha}$

$A_{1}=(0.415-0.071 \alpha) \sigma_{\max } / \sigma_{0}$

$A_{2}=1-A_{0}-A_{1}-A_{3}$

$A_{3}=2 A_{0}+A_{1}-1$

Cyclic damaged zone evolution:

$\Delta D_{c}=\int_{t_{1}}^{t_{2}} \dot{D}_{c} \mathrm{~d} t=\int_{0}^{1} \frac{\mathrm{d} D_{c}}{\mathrm{~d} N} \mathrm{~d} N$

$\frac{\mathrm{d} D_{c}}{\mathrm{~d} N}=-\frac{\mathrm{d} a_{c}}{\mathrm{~d} N}$

Cyclic scale function:

$S_{c}=1+A_{c}\left(\frac{D}{D_{\max }}\right)^{B_{c}} \quad A_{c}, B_{c} \geq 0$ 
In Table 1 the parameter $D_{\max }$ represents the maximum size of the damaged zone under stationary conditions, while $C_{0 t}, B_{t}, n_{t}, C_{c}, A_{c}$ and $B_{c}$ are fitting parameters. By incorporating the crack closure routine by Newman [15] for handling the different $R$-values $\left(\sigma_{\min } / \sigma_{\max }\right)$ associated with rapid cyclic loading (type (ii)), an effective way to handle considered spectrum loadings is accomplished, here expressed as in [16], and seen in Table 1 as the expression $(1-f) /(1-R)$. The function $f$, introduces the parameter $\alpha$ (constraint parameter), and the ratio $\sigma_{\max } / \sigma_{0}$, also treated as a parameter.

All the following simulations were done using MATLAB and the optimisation of the model parameters was done by the commercial software LS-OPT [17] in combination with FORTRAN, by minimisation of a least square based error function.

Calibration. To handle the calibration of the fitting parameters in Table 1, a specially designed test was performed in order to capture multiple constants with a minimum amount of resources, see also $[11,12]$. The test is described in Fig. 1 (performed with $\sigma_{\max }=650 \mathrm{MPa}$ ) and captures the two trend lines (in a log-log plot); continuous cycling $(0.5 \mathrm{~Hz}, R=0.05)$, to a crack length of $0.55 \mathrm{~mm}$, with no damaged zone, i.e. baseline level, and the one for constant loading, to a crack length of 1.8 $\mathrm{mm}$. Finally, the calibration test is completed by a cycling to a crack length of $2.6 \mathrm{~mm}$, where again a stabilised baseline level is reached. The transients seen in between these steady state regions will be used for extracting the fitting parameters $B_{t}, A_{c}, B_{c}$ and to determine the value of $D_{\max }$. For more information about the maximum damaged zone, cf. [10].

To compensate for crack closure a new $C_{c}$ value was derived from the one experimentally given in Fig. 1, i.e. by using $\alpha=2.5$ and $\sigma_{\max } / \sigma_{0}=0.3$. The derived parameter $C_{c}$ was confirmed by using an $R=0.6$ test ( $\sigma_{\max }=650 \mathrm{MPa}, 0.5 \mathrm{~Hz}$ ) as validation.

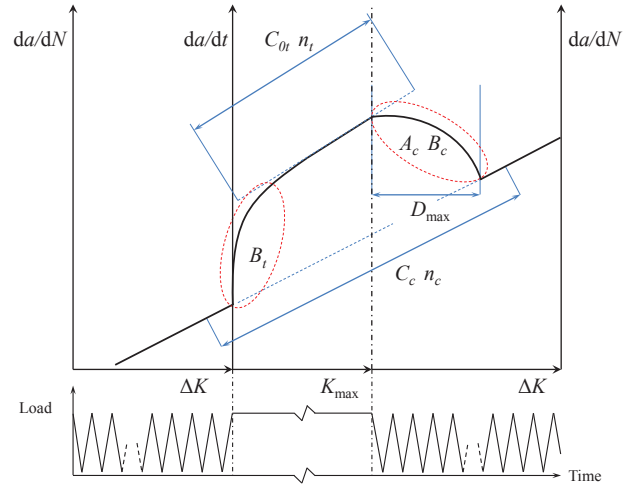

(a)

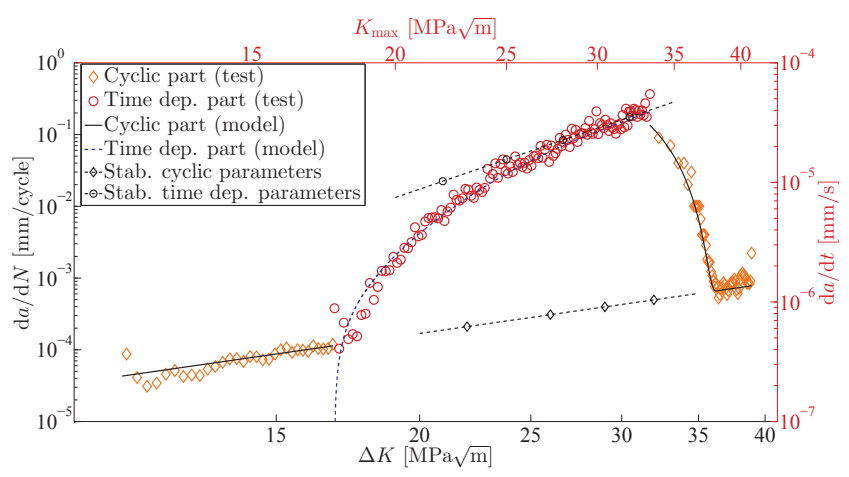

(b)

Figure 1: Calibration test. (a) Principle for parameter determination and (b) mechanical test result.

All optimised model parameters are summarised in Table 2, where it is to be noted that the stress intensity factors in Paris law must be given in $\mathrm{MPa} \sqrt{\mathrm{m}}$, and that the crack growth rates are in $\mathrm{mm} / \mathrm{s}$ or $\mathrm{mm} / \mathrm{cycle}$, and finally that the maximum length of damaged zone $D$ is also given in $\mathrm{mm}$.

Table 2: Model parameters.

\begin{tabular}{llllllllll}
\hline$C_{0 t}$ & $n_{t}$ & $C_{c}$ & $n_{c}$ & $B_{t}$ & $A_{c}$ & $B_{c}$ & $D_{\max }$ & $\alpha$ & $\sigma_{\max } / \sigma_{0}$ \\
\hline $3.9 \times 10^{-10}$ & 3.3 & $3.3 \times 10^{-7}$ & 2.3 & 0.35 & 331 & 2.7 & 0.5 & 2.5 & 0.3 \\
\hline
\end{tabular}

\section{Results}

The model presented above is applied to a flight spectrum containing hold times of varying kinds, both stationary loading with enough low frequency for the crack growth to be considered time dependent, and rapidly applied load cycles for a wide range of $R$-values; the spectrum is presented in Fig. 2. 


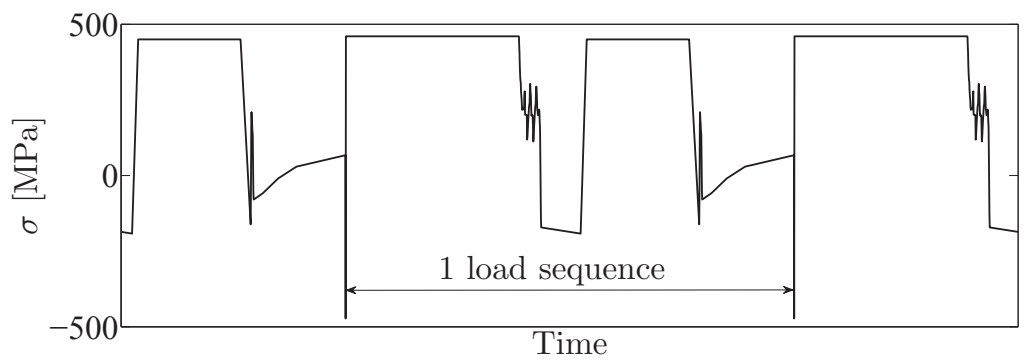

Figure 2: Flight spectrum.

From the spectrum in Fig. 2 the different load cycle types and stress ranges were identified through a manual filtering process based on the following assumptions: (1) cyclic fatigue crack growth occurs only during the loading part of a cycle, as also suggested by [18], (2) no hold time effect is present during negative loads, and finally, (3) the hold time effect is absent during the parts of the spectrum that has already been considered under part (1) above; the process is summarised in Fig. 3.

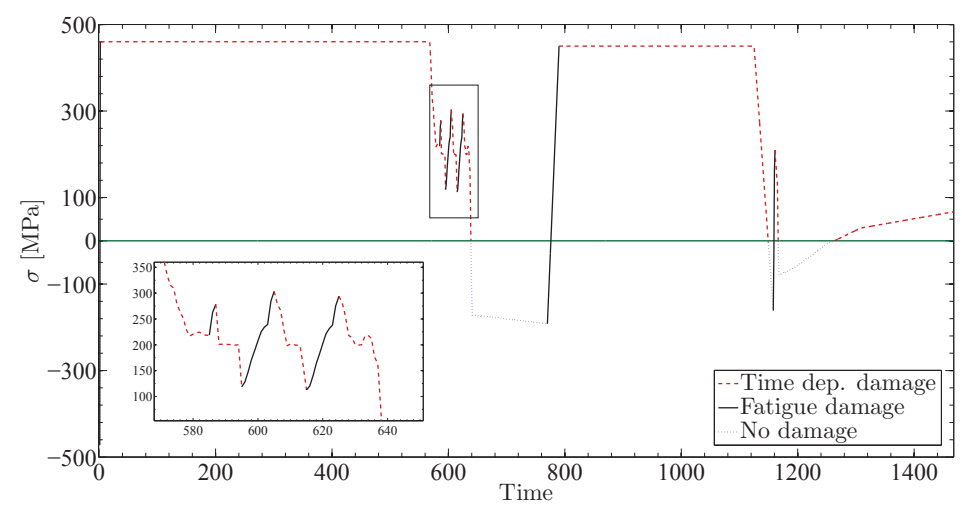

Figure 3: Damage definition of the flight spectrum.

The time span of each spectrum is, as can be seen in Fig. 3, $1468 \mathrm{~s}$. The test was run from an initial crack length of about $1.05 \mathrm{~mm}$ to a final length of about $2.45 \mathrm{~mm}$, representing a total of approximately 566 spectrums, and a total test time of about 9.6 days. Results for crack length vs. time can be seen in Fig. 4a, while in Fig. 4b the predicted damaged zone evolution can be found; the simulation resulted in a total life time of about 8.3 days which gives an error of roughly $13 \%$ compared to the actual test.

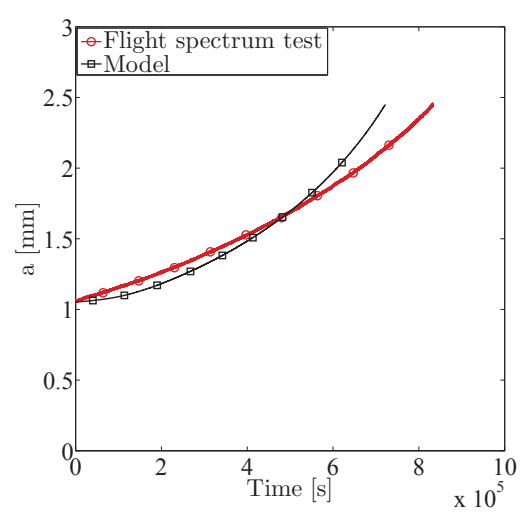

(a)

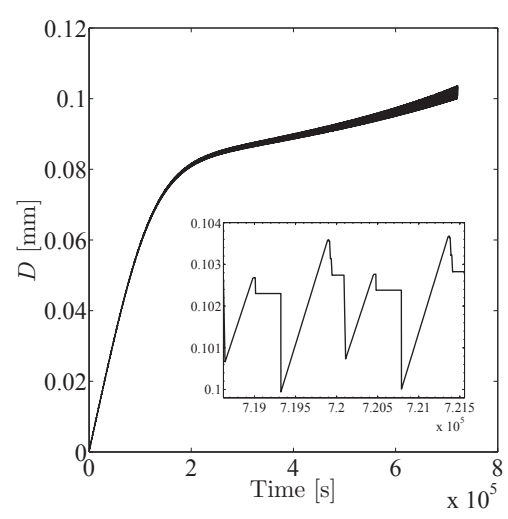

(b)

Figure 4: Results for the analysed flight spectrum (a) crack length vs. time and (b) damaged zone evolution. 


\section{Discussion}

When evaluating the spectrum one can see from Fig. $4 \mathrm{~b}$ how the damaged zone is progressively built up during the hold times and subsequently destroyed during the rapid cyclic loading, and by this controlling the crack propagation rate. Due to the inherent structure of the model, the hold time damage length will never reach its maximum value for other cases than sufficiently long hold times, where the maximum damaged zone size is obtained. Further, the damaged zone size is repeatedly reduced by rapid load reversals, associated with high crack growth rates due to propagation in partly damaged material of low resistance to crack growth. Thus, with the crack growth law used in Table 1, one can assure that the current crack growth rate is always in range of what the previous load history implies. Comparing this model to a more classical approach where the hold time damage is characterized with fully developed time dependent constants, and with cyclic parameters which are not dependent on the load history (damaged zone), the result clearly shows the benefits of the model used in this paper; see Fig. 5 where the same model (evaluated on the same spectrum) has been used except with the modification that $C_{t}=C_{0 t}$ on the time dependent part and $D=0$ on the cyclic part, thus achieving a non-history dependent model. Also, in Fig. 5, the result for the same spectrum but with no hold time effect present is shown, achieved by simply setting $\sigma=0$ on the hold time parts. This shows how important it is to take the hold time effect into account, independently of what model that is used.

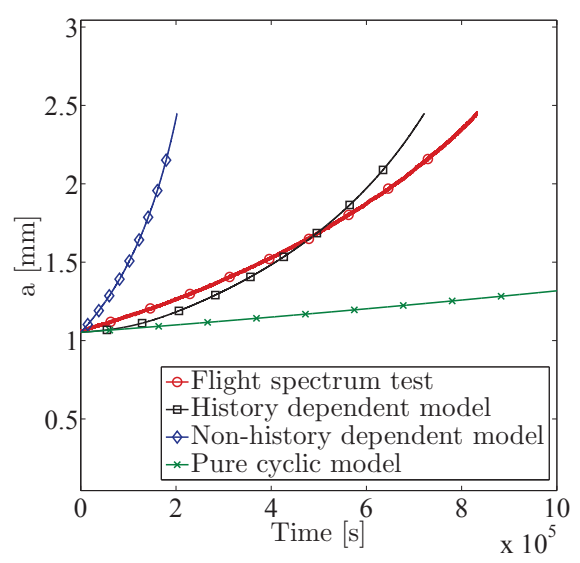

Figure 5: Crack length vs time, with $C_{t}=C_{0 t}$ on each time dependent part and $D=0$ on each cyclic part, and the result without any hold time effect, here with $\sigma=0$ on the hold time parts.

Although the model used in this paper works well for the flight spectrum presented, with distinct regions of very low stress rates and rapid cyclic loadings, the model is in its current state still not tested for applications involving slow transient loads, e.g. sine waves of low frequency. Since no hold time test with varying frequency has been available for further calibration and model development, and as one cannot know if the damaged zone growth rate is retarded when the loading frequency reaches some kind of threshold or transition value (from intergranular to transgranular crack growth mode, although this matter is discussed in e.g. $[1,18]$ ), work is still needed to incorporate this into the damaged zone concept used in this paper.

\section{Summary}

Simulation of a relevant aero engine spectrum at $550{ }^{\circ} \mathrm{C}$ for a surface crack has been performed by using a history dependent fatigue crack propagation model and incorporating crack closure to handle the $R$-value dependence. The obtained simulation results show a good correlation to test data. 


\section{Acknowledgements}

The authors would like to thank Mr. Patrik Härnman and Mr. Bo Skoog, Linköping University, for the laboratory work and the project teams at Linköping University, Siemens Industrial Turbomachinery $\mathrm{AB}$ and GKN Aerospace Engine Systems, for valuable discussions. This research has been funded by the Swedish Energy Agency, Siemens Industrial Turbomachinery AB, GKN Aerospace Engine Systems, and the Royal Institute of Technology through the Swedish research programme TURBO POWER, the support of which is gratefully acknowledged.

\section{References}

[1] T. Weerasooriya: Air Force Wright Aeronautical Laboratories Report, AFWAL-TR-87-4038, Wright-Patterson Air Force Base, OH (1987)

[2] A. Pineau and S.D. Antolovich: Engineering Failure Analysis Vol. 16(8) (2009), p. 2668

[3] K.O. Findley, J.L. Evans and A. Saxena: International Materials Reviews Vol. 56(1) (2011), p. 49

[4] T. Nicholas and T. Weerasooriya: Fracture Mechanics: Seventeenth Volume, ASTM STP 905, (1986), p. 155

[5] J. Gayda, T.P. Gabb and R.V. Miner: Low Cycle fatigue, ASTM STP 942 (1988), p. 293

[6] H. Ghonem and D. Zheng: Materials Science and Engineering: A Vol. 150(2) (1992), p. 151

[7] D. Zheng and H. Ghonem: Fatigue \& Fracture of Engineering Materials \& Structures Vol. 14(7) (1991), p. 761

[8] L.G. Zhao, J. Tong and M.C. Hardy: Engineering Fracture Mechanics Vol. 77(6) (2010), p. 925

[9] U. Krupp: International Materials Reviews Vol. 50(2) (2005), p. 83

[10] D. Gustafsson, J.J. Moverare, S. Johansson, K. Simonsson, M. Hörnqvist, T. Månsson and S. Sjöström: International Journal of Fatigue Vol. 33(11) (2011), p. 1461

[11] D. Gustafsson, E. Lundström and K. Simonsson: International Journal of Fatigue Vol. 52 (2013), p. 124

[12] E. Lundström, K. Simonsson, D. Gustafsson and T. Månsson: submitted (2013)

[13] J.C. Newman, Jr. and I.S. Raju: Technical report, NASA Technical Memorandum 85793, (1984)

[14] D. Gustafsson, J.J. Moverare, S. Johansson, M. Hörnqvist, K. Simonsson, S. Sjöström and B. Sharifimajda: Procedia Engineering Vol. 2(1) (2010), p. 1095

[15] J.C. Newman, Jr.: International Journal of Fracture Vol. 24 (1984), p. R131

[16] NASGRO manual 6.0, SwRI

[17] N. Stander, W. Roux, T. Goel, T. Eggleston and K. Craig: LS-OPT User's manual, Version 4.2, Livermore Software Technology Corporation, Livermore, CA (2011)

[18] H. Ghonem, T. Nicholas and A. Pineau: Fatigue \& Fracture of Engineering Materials \& Structures Vol. 16(5) (1993), p. 565 